\title{
Talking about Taste: Disagreement, Implicit Arguments, and Relative Truth
}

\author{
Isidora Stojanovic \\ Institut Jean Nicod, CNRS - Ecole Normale Superieure, 29 rue d'Ulm, Pavillon Jardin, 75005 Paris, France \\ Isidora.Stojanovic A T ens.fr
}

\begin{abstract}
In this paper, I take issue with an idea that has emerged from recent relativist proposals, and, in particular, from Lasersohn (2005), according to which the correct semantics for taste predicates must use contents that are functions of a judge parameter (in addition to a possible world parameter) rather than implicit arguments lexically associated with such predicates. I argue that the relativist account and the contextualist implicit argument-account are, from the viewpoint of semantics, not much more than notational variants of one another. In other words, given any sentence containing a taste predicate, and given any assignment of values to the relevant parameters, the two accounts predict the same truth value and are, in that sense, equivalent. I also look at possible reasons for preferring one account over the other. The phenomenon of "faultless disagreement" (cf. Kölbel (2002)) is often believed to be one such reason. I argue, against Kölbel and Lasersohn, that disagreement is never faultless: either the two parties genuinely disagree, hence if the one is right then the other is wrong, or the two parties are both right, but their apparent disagreement boils down to a misunderstanding. What is more, even if there were faultless disagreement, I argue that relativism would fail to account for it. The upshot of my paper, then, is to show that there is not much disagreement between a contextualist account that models the judge parameter as an implicit argument to the taste predicate, and a relativist account that models it as a parameter of the circumstances of evaluation. The choice between the two accounts, at least when talking about taste, is thus, to a large extent, a matter of taste.
\end{abstract}


Talking about Taste: Disagreement, Implicit Arguments and Relative Truth / 2

\section{Section 1. Setting the Stage}

Predicates of personal taste give rise to a puzzle. Consider this dialogue between Tarek and Inma, who have just tasted some soybean ice-cream:

1. Tarek: This is delicious.

2. Inma: That's not true. This isn't delicious at all.

On the one hand, we are inclined to say that Tarek and Inma disagree. But on the other hand, we are also inclined to say that Tarek and Inma may both be right, and that their seemingly contradictory utterances may be true together. So here comes a puzzle:

a: For any two utterances $u_{1}$ and $u_{2}$, the utterer of $u_{1}$ disagrees with the utterer of $u_{2}$ only if: if $u_{1}$ is true, then $u_{2}$ is false, and if $u_{1}$ is false, then $\mathrm{u}_{2}$ is true.

b: $\quad$ The utterer of (1) (Tarek) disagrees with the utterer of (2) (Inma).

c: On the assumption that Tarek finds the soybean ice-cream delicious, and that Inma does not, (1) is a true utterance, and so is (2).

The problem is that $a, b$ and $c$, while plausible on their own, lead to contradiction.

For relativists like Peter Lasersohn and Max Kölbel, the way out of the puzzle lies in rejecting a. ${ }^{1}$ My own way out of the puzzle will be to reject either $b$ or $c$, on a case to case basis. I will argue that the puzzle arises from some equivocation upon the notion of disagreement. In the weak sense, disagreement means that the two parties take each other to be saying false things. However, note that this may happen simply because one party misinterprets the other party. Disagreement is genuine only when the one party's being right entails that the other party is wrong. My goal in

1 Cf. Lasersohn: "If you say that roller coasters are fun, and I say they are not, I am negating the same content which you assert, and directly contradicting you. Nonetheless, both our utterances can be true (relative to their separate contexts)" (2005: 645). A similar proposal may be found in Kölbel (2002). Let me stress from the outset that John MacFarlane does not share Kölbel's and Lasersohn's views regarding the issue of "faultless disagreement"; see MacFarlane (2007). 
Section 2 will thus be to show that any prima facie case of faultless disagreement distills, upon analysis, either into a case of genuine disagreement with only one party being right, or into a case of spurious disagreement based upon a misunderstanding.

In Section 3, I will argue that even if we were to accept, for the sake of the argument, that there can be faultless disagreement on matters of taste, the mere idea of truth relative to a judge, and the related idea of content whose truth value varies along the judge parameter, would not yet suffice to account for the phenomenon. In other words, relativism, when understood as a proposal regarding the notion of (semantic) content, is not any more apt to handle faultless disagreement than contextualism. But this should come as little surprise since, as I show in Section 4, a relativist framework of the sort proposed in Lasersohn (2005) can be put into a oneone correspondance with a contextualist framework that handles the judge-dependence of taste predicates by means of implicit arguments. The

upshot of the technical result from Section 4 is to show that if a compelling argument is to be made for relativist semantics, and against contextualist semantics, it cannot rely on there being cases in which the former but not the latter gives a correct prediction of truth value. In Section 5, I discuss further considerations that, at a first glance, seem to tell in favor of the relativist account, and against the contextualist account, and that turn upon the question of what we say when we talk about taste. I will conclude, though, that those considerations are far from being conclusive.

\section{Section 2. Disagreement vs. Misunderstanding}

In this section, I will argue that there is no such phenomenon as faultless disagreement: either the disagreement is genuine, but only one party gets it right, or else, it is spurious and boils down to a misunderstanding.

Reconsider the dialogue in (1)-(2). I will try to show that considerations about the context in which the dialogue arises, and about the ways in 
which it may evolve, make it possible to decide whether we have a case of genuine disagreement, or only disagreement due to a misunderstanding.

Let me first note that acknowledging that one has been talking about one's own taste strongly suggests that there was no genuine disagreement in the first place. Thus one way in which Inma and Tarek may resolve their dispute would be to recognize that what may be delicious for the one need not be delicious for the other:

3. Tarek: OK. To my taste, this ice-cream is delicious; that's all I'm saying.

4. Inma: $\mathrm{OK}$, and to my taste, it isn't delicious at all; that's all I'm saying.

In (3) and (4), Tarek and Inma make it explicit that in discussing whether the ice-cream was delicious, they meant to be talking of themselves and of their own tastes, and, therefore, did not really mean to contradict each other - as they acknowledge themselves, having moved from "Oh yes/Oh no" dialogue to "OK/OK" dialogue.

Now, even though, in matters of taste, people sometimes reach some kind of agreement by realizing that they like different things and that their taste matters to the truth of their statements, at other times they persist disagreeing, as if there were a matter of fact as to whether a given thing had a given property (such as deliciousness) or not. Tarek and Inma may never resolve their disagreement, even after they have come to realize that the truth of their utterances may vary with taste:

5. Tarek: This is delicious! And it's not just that I find it delicious; it's delicious tout court.

6. Inma: No, that's not true. It isn't delicious - though I can see that people may find it delicious.

What do speakers who disagree on whether something is delicious tout court actually disagree about, if the truth of what they say depends indeed on a particular judge and his or her taste? If such speakers are aware that what they say cannot be evaluated for truth unless a judge, or a point of view, has been supplied, and if they supply different judges, they must 
realize that their seemingly contradictory utterances may be simultaneously true, simply because of being evaluated at different judges. But, as we have seen with (3)-(4), there would be no matter for disagreement in such a case.

A plausible answer is that in the case of genuine disagreement, the two parties agree on the value supplied to the judge parameter, but disagree as to whether with respect to that value, a given thing is delicious or not. Of course, it is unlikely that the judge agreed upon will be either of the two parties. Rather, when Tarek says that the ice-cream is delicious tout court, and when Inma denies this, what is likely to be at stake is that they disagree as to whether the ice-cream is delicious on some universally or at least generally accepted standards. They cannot be both right, so in this respect, their disagreement is on a par with ordinary disagreement about facts. To resolve it, Inma and Tarek would need to determine whether the ice-cream is delicious according to such general standards. To be sure, there remains the issue of how that can be determined - perhaps by carrying out a survey. ${ }^{2}$ But, more importantly, whatever makes it possible to determine whether something is delicious with respect to any particular judge will also make it possible to determine whether it is delicious in general, since one would only need to determine whether for most judges, the thing is delicious with respect to them. Note that this issue does not pertain to semantics, hence neither the relativist nor the contextualist are required to address it.

Now, disagreement, in the weak sense of simply taking the other party to be saying something false, may also result from a misunderstanding. Reconsider (1)-(2), but suppose that when Tarek utters (7) below, he is holding in his fingers a waffle that came with the ice-cream:

2 A survey will only work if we assume that every person knows best what is delicious for him or her. Expressing one's own taste is, in this respect, similar to reporting one's own beliefs: if I sincerely say that I believe something, it seems that I cannot go wrong. However, whether a person's sincere assent to a sentence like "This is delicious for me" warrants that the thing at stake is indeed delicious for that person is an issue orthogonal to the contextualism/relativism debate. 
7. Tarek: This is delicious!

8. Inma: That's not true. This isn't delicious at all.

Tarek still means to be saying of the ice-cream that it is delicious, but fails to realize that Inma is likely to take him to be referring to the waffle. Inma, too, thinks that the ice-cream is delicious; what she means to be denying in (8) is that the waffle is delicious, which she takes Tarek to be talking about in (7).

It often happens that people engage in a dispute, while there are virtually no facts over which they disagree. Tarek thought that with 'this' he could unambiguously refer to the ice-cream, yet Inma justifiedly took him to be referring to the waffle. However, they failed to realize that their "disagreement" was simply due to a lack of agreement on what they were talking about. Now, I submit that many cases of prima facie disagreement on matters of taste similarly result from a lack of agreement on how to understand each other. If in saying that something is delicious, Tarek means to express his own predilections, and if in denying that it is delicious, Inma wishes to express her own dislike of it, then they should not persist disagreeing, unless they were confused as to what the other person, or even themselves, mean to be expressing.

Let me close this section with an example that Lasersohn believes to be particularly problematic for the contextualist. Imagine Mary and John riding on a roller-coaster and saying:

9. Mary: This isn't fun!

10. John: Oh, yes it is!

Lasersohn wants to claim that no contextualist proposal can account for the disagreement in this case. In particular, he thinks that neither a universal nor a generic reading would give us disagreement. As for the universal reading, he points out that it would imply that John claims that the ride is also fun for Mary, which he takes to be implausible:

“By contradicting her, John must be acting irrationally, or ignoring 
what Mary said, or claiming to know her own mind better than she does herself, or something similar. But in fact in this example John does not seem to be doing any of those things." (2005: 651)

The problem is that when Lasersohn talks of "this" example, he hasn't really told us what the example is. We are only given the sentences that Mary and John uttered, but to know what they are doing - whether they are really disagreeing, or just expressing different preferences, or talking past each other, we need more information on the context. In particular, we need to know in which way they could resolve their disagreement (if ever). For, it is certainly true that in some cases, John will be doing some of the things that "he does not seem to be doing," like claiming to know better than Mary what is fun for her. And if he presented her with solid arguments, he could even convince her that the ride was fun for her, even though initially she wasn't prepared to accept it - just as a psychotherapist may convince a patient that she believed something she thought she didn't believe.

As for the suggestion that disagreement may be explained by endowing (9) and (10) with a weaker generic reading, Lasersohn writes:

"It does not seem right that in order to analyze John and Mary as contradicting each other in examples like [(9)-(10)], we must treat their disagreement not as a matter of their own conflicting views about the roller coaster, but as a disagreement about what the majority view is within some group. If Mary has ridden on the roller coaster and knows that she does not like it, surely John will not be able to convince her that is is fun by showing her the results of a survey!" (2005: 652)

Here again, Lasersohn's argument turns upon equivocation. What John will not be able to convince Mary with the results of a survey is that the roller coaster is fun for her. But what he ought to be able to convince her (assuming that she is rational and accepts that everyone knows best what is fun for them) is that the roller coaster is fun for the majority. In other words, the phrase 'to convince someone that something is fun' is in need 
Talking about Taste: Disagreement, Implicit Arguments and Relative Truth / 8

of disambiguation.

\section{Section 3. Can Relativism Account for Faultless Disagreement?}

Lasersohn's argument for a relativist account of taste predicates proceeds by elimination. He starts with cases that trigger the intuition of faultless disagreement, then argues that none of the available accounts can explain them. My discussion in the previous section already serves as a rebuttal of his argument, since if genuine disagreement entails that one of the parties is wrong, there is no phenomenon of faultless disagreement to begin with. I will now argue that even if there were faultless disagreement, a relativist proposal of the sort put forward in Lasersohn (2005) would not be able to account for it. $^{3}$ My argument relies on an assumption endorsed equally well by relativists as by contextualists:

Semantic Competence (SC):

Speakers of English are semantically competent with predicates of taste: they master their meaning and truth conditions.

It is clear enough why anyone who believes in faultless disagreement should subscribe to SC. For, if it turned out that the disagreeing parties were ignorant about the way in which taste predicates behave and contribute to truth conditions, then the disagreement would be merely a by-product of semantic ignorance. For disagreement to be genuine (be it faultless or not), we must presuppose that the disagreeing parties master the meaning of the words with which they are expressing disagreement.

Leaving formal details aside, Lasersohn's proposal is that the content expressed by (an utterance of) a sentence "This is tasty" is a function from pairs consisting of a possible world and a judge, into truth values. ${ }^{4}$ Thus when Tarek utters this sentence, talking about the soybean ice-cream, and

3 My argument also applies to the proposal put forward in Kölbel (2002).

4 For the sake of simplicity, I ignore the time parameter throughout my paper. Also, the truth value of sentences containing taste predicates, just as with gradable adjectives in general, may be affected by shifting the comparison class. For simplicity, I also ignore variability along comparison classes (but see e.g. Glanzberg (2007) for discussion). 
when Inma denies it, they express contradictory contents, yet both utterances may be true, so long as they are evaluated at different judges (or, for that matter, at different worlds).

Assume, for the sake of the argument, that the relativist proposal is correct. Then, given SC, Tarek knows that the content that he is asserting is true or false depending not only on what the world is like, but also on the judge. The same goes for Inma when she denies the content asserted by Tarek. Now, if Tarek intends the content that he is asserting to be evaluated for truth at himself, and if Inma intends her content to be evaluated for truth at herself, that will undermine the idea that their disagreement is genuine and rational. Both of them, given SC, know that one and the same content may take different truth values when evaluated at different judges. They also know that the one's assertion and the other's denial of the same content are inconsistent only when evaluated with respect to the same judge. Hence if each party intends the asserted content to be evaluated at himself or herself, and if this is mutually clear between them, then they will realize that there is no clash in truth value between their claims (when evaluated as they intend them to be), and that their "disagreement" is thus nothing more than a divergence in preferences. ${ }^{5}$

To forestall a possible misunderstanding, the above argument does not presuppose that the speaker's intentions determine the judge at which the asserted content is, or ought to be, evaluated for truth. It only presupposes that a (semantically competent) speaker who aims at asserting truth, and asserts a content whose truth value depends upon a judge, will intend this

5 The analogy with the modal case may help illustrate the point. Given SC, speakers are aware that what they assert may be true at the actual world while being false at some counterfactual state of affairs. We often forget about this, because the world talked about is, by default, the actual world. But claims are sometimes meant to be evaluated for truth at some other world, as when we talk about fiction (cf. Predelli (2005a: 54)). Thus if Tarek says that Holmes lived on Baker Street while talking about the fictional world of Conan Doyle's novels, and if Inma denies this, but is talking of the actual world, they are not really disagreeing. By analogy, it is not clear why we should take them to be disagreeing when Tarek says that the soybean ice-cream is delicious and Inma says that it isn't, when each is talking of his or her own taste. 
content to be evaluated for truth at a particular judge. While Lasersohn explicitly rejects the former assumption, he would probably agree with the latter.

Another important aspect of Lasersohn's proposal is that "the objective facts of the situation of utterance do not uniquely determine a judge" (2005: 669). Now, if that is the main tenet of relativism, then I submit that there are many more expressions that deserve a similarly "relativist" treatment. Reconsider the dialogue back in (7)-(8). If Tarek's intention is to say something about the ice-cream, while his interlocutors are likely to take him to be talking about the waffle, the objective facts of the situation of utterance will not determine the one object rather than the other as that which will, in turn, determine the truth value of his utterance. Regardless of we think of the resolution of demonstrative reference in that particular case, the important point is that we may well grant the relativist that the situation of utterance does not determine the judge - but that will not yet give us an account of faultless disagreement. ${ }^{6}$

Now, the question of what determines the values assigned to the various parameters of context and of evaluation, which in turn determine the truth value assigned to a sentence (as used on a given occasion), is sometimes taken to be precisely the question on which relativism departs from contextualism. If, following John MacFarlane, one distinguishes between contexts of utterance and contexts of assessment, one could reframe the contextualism/relativism debate by stipulating that in the contextualist view, it is always the context of utterance that determines the values of the parameters needed to determine the truth value, while in the relativist view, it is always the context of assessment. So, for instance,

6 Lasersohn was probably aware that something had to be added to his relativist semantics in order to achieve faultless disagreement. Recall the dialogue in (9)-(10), in which Mary and John appear to disagree on whether the roller-coaster ride is fun. Lasersohn goes on to suggest that each party is "asserting his or her own perspective over and against that of the other" (2005: 652; my italics). Though it is not entirely clear what he means by 'asserting a perspective' or how his own proposal is supposed to account for the idea, it may be that he is hinting here at some deeper form of relativism than what he actually spells out in his paper. 
when Tarek says that the ice-cream is delicious, the contextualist would say that the judge (who may be Tarek, but need not), and, thereby, the truth value, is determined in the context of utterance, while the relativist would say that any context from which Tarek's utterance is assessed for truth or falsity determines a possibly different judge, hence a possibly different truth value.

This way of reframing the debate allows for cases in which contextualism and relativism predict different truth values. However, I am not convinced that this is how we should understand the debate, for the following reasons. Lasersohn's relativism is presented, first and foremost, as a proposal about semantics. He defends the idea that semantic contents are functions from (inter alia) judges to truth values, and argues against views that handle the judge-dependence by means of implicit arguments. ${ }^{7}$ But if we think of semantics as a theory that provides recursive definitions of truth conditions, then the task of determining which values to assign to the parameters deployed in those definitions in order to evaluate a sentence, on a particular use, for its truth value, will not belong to semantics. Reframed as above, the contextualism/relativism debate is no longer a semantic debate. ${ }^{8}$

More importantly, traditional contextualist views as not committed to the idea that the situation of utterance uniquely determines the values of the parameters that will determine the truth value. As noted above, even with demonstrative pronouns, the resolution of reference is not (or, at least, not necessarily) carried out in the situation of utterance. Kaplan

7 In fairness to Lasersohn, he recognizes as an "alternative approach" a proposal that uses a hidden argument for the judge (2005: 678-682), but seems to think that such a proposal would require a major departure from traditional semantics.

8 By saying that thusly reframed, the debate between contextualism and relativism will no longer be a semantic debate, I do not mean to underestimate its interest. To the extent that the values assigned to the parameters under consideration have an impact on truth value, one might want to say that the question of how to fix those values is indeed very relevant to semantics. On the other hand, it is beyond controversy that number of pragmatic factors must be deployed in fixing those values. In this sense, the debate appears to sit squarely at the semantics/pragmatics interface. 
himself, for instance, insisted that his notion of 'context' was a theoretical artefact, not to be confused with the intuitive notion of a context of utterance. The issue of which Kaplanian context, i.e. sequence of values 〈agent, location, time, world $\rangle$, is to be associated with some sentence in order to obtain a truth value for an utterance of that sentence, does not have to be addressed by (semantic) contextualism. ${ }^{9}$

Finally, even if we grant the relativist that the context of assessment, rather than the context of utterance, determines the judge who, in turn, determines the truth value, it is unclear that this could help explaining faultless disagreement. Dependence of taste predicates on a context of assessment will now be built into their semantics, and the assumption of semantic competence will give us that a speaker who makes a claim on a matter of taste must be aware that his or her claim can only be evaluated for truth with respect to a context of assessment. If Tarek intends his claim to be evaluated with respect to his own context of assessment, while Inma intends her denial of Tarek's claim to be evaluated with respect to her own context, and if this is mutually clear between them, then we have hardly advanced towards an explanation of their presumed disagreement. (Of course, if they are not aware that their claims are meant to be evaluated with respect to different contexts, they may well persist disagreeing, but their disagreement would then involve some form of misunderstanding and fail to qualify as genuine and rational. $)^{10}$

\section{Section 4. Implicit Arguments vs. Relative Truth: What Difference Does It Make?}

9 Predelli (2005a), (2005b) convincingly argues at length that the task of deciding which values to assign to the contextual parameters and parameters of evaluation in order to assign a truth value to a sentence on a particular use does not pertain to semantics.

10 MacFarlane appears to be confortable with the idea that disagreement on matters on taste is not entirely rational: "From lofty philosophical heights, the language games we play with words like 'funny' and 'likely' may seem irrational. But that is no reason to deny that we do play these games, or that they have a social purpose" (2007: 49). 
In this section, I will show that contextualist semantics (CS), in which the judge parameter is treated as an implicit argument to the taste predicate, and relativist semantics (RS), in which it is treated as a parameter in the circumstance of evaluation, do not differ interestingly, since they yield the same truth predictions. ${ }^{11}$

Before I proceed, let me point out something to bear in mind. The frameworks that I shall show to be equivalent are bare semantic frameworks, in the sense that neither says how, in practice, values get assigned to implicit arguments or to parameters of evaluation. In light of the discussion from the previous section, there is no reason to think that the equivalence would go through if we built into either framework extrasemantic assumptions that would say that in the one case it is, say, the context of utterance that fixes those values, and in the other, something else, like a context of assessment (MacFarlane) or a "pragmatic context" (Lasersohn). My main target in this section is the idea that the success of relativism and the failure of contextualism may be measured at the level of the semantics itself. ${ }^{12}$ My claim that, qua semantic frameworks, relativism and contextualism do not differ interestingly, presupposes that we understand semantics as concerned with recursive assignments of truth conditions, but unconcerned with the task of determining which

11 The contextualist semantics that lends itself to the equivalence result uses a minimum of its resources: it allows at most one implicit judge argument per atomic sentence, while all free occurrences of this argument within a sentence are assigned the same value. For the present purposes, it is more important to show that CS can do anything that RS can do, rather than the other direction, which is why it is safe to choose this weak version of CS. Also, it is beyond the scope of this paper to compare the behavior of the implicit judge argument with that of better known implicit arguments. For the latter, see e.g. Partee (1989) or Condoravdi and Gawron (1996).

12 Lasersohn stresses on several occasions that he is presenting a semantics that he thinks can give results than other semantic frameworks cannot (2005: 645; 681). In particular, he is keen to reject the option which "analyze(s) sentences containing fun, tasty, etc. as making indexical reference to some relevant individual or group, not necessarily the speaker" (650), which I take to correspond to contextualist semantics (unless something very specific is meant by 'indexical reference'). Note that others, too (e.g. Glanzberg (2007) or Stephenson (2007)) have interpreted Lasersohn's proposal as bearing primarily on the semantics of predicates of taste. 
assignments of values (to variables or any other parameters) are relevant to determining the truth value of a sentence on a particular use.

To prove the equivalence between CS and RS, I define a bi-directional translation procedure $T$ between the two formal languages for which the following holds. Let $S_{c}$ and $S_{r}$ be respectively sentences in the languages of CS and of RS, let $f_{1}, f_{2}$ be assignments of values to free variables, and let $w$ be a world of evaluation and $u$ a judge. Then:

- $S_{r}$ is true with respect to $f_{1}, w$ and $u \underline{\text { iff }} T\left(S_{r}\right)$ is true with respect to $f_{1}^{T}$ and $w$, where assignment $f_{1}{ }^{T}$ is defined in terms of $f_{1}$ and $u$.

- $S_{c}$ is true with respect to $f_{2}$ and $w$ iff $T\left(S_{c}\right)$ is true with respect to $f_{2}, w$ and $u^{T}$, where $u^{T}$ is a judge value obtained directly from $f_{2}$.

The method that I am using is classic, and the result obtained, qua a formal result, is well known within model theory for modal logics. ${ }^{13}$ But it is still worthwhile to lay down the equivalence, as it appears to be widely neglected by both camps in the contextualism/ relativism debate.

Let us start with contextualist semantics. Its formal language, $\mathrm{L}_{\mathrm{CS}}$, is the language of quantified modal logic, the only novelty being that we have a distinguished variable, $\mathrm{x}_{\mathrm{T}}$, used for the implicit judge argument associated with taste predicates. The syntax of $\mathrm{L}_{\mathrm{CS}}$ consists of the standard rules for well-formedness, plus the constraint that for any atomic sentence, $x_{T}$ occurs at most once, and only in the very last position. ${ }^{14}$

On the semantic side, a structure is a triple consisting of a universe, a set of possible worlds, and a valuation that maps n-place predicates to functions that map possible worlds to sets of n-tuples of individuals. For

13 In essence, the equivalence between the relativist and the contextualist semantics of taste predicates (when the latter disallows multiple judge arguments) derives from the equivalence between modal logic S5 and monadic predicate logic.

14 For example, $\mathrm{Px}_{\mathrm{T}} \mathrm{x}_{\mathrm{T}}$ and $\mathrm{Px}_{\mathrm{T}} \mathrm{y}$ are not well-formed, while $\mathrm{Pyy}$ or $\mathrm{Pyx}_{\mathrm{T}}$ are. We need the "at most once" constraint for the equivalence results. However, the language thus constrained seems fine for modeling natural language, because, at least in English, we do not seem to have atomic expressions that simultaneously involve two judges. As for the constraint that $\mathrm{x}_{\mathrm{T}}$ always occurs at the end, it is only there to make it easier to define the translation between the two formal languages, but nothing important hinges on it. 
simplicity, I will ignore accessibility relations. Truth is recursively defined with respect to models, i.e. triples consisting of a structure, a world, and an assignment of values to free variables. The truth definitions are entirely standard: e.g. $\mathrm{S}, \mathrm{w}, \mathrm{f} \vDash \square \mathrm{F}$ iff def $_{\text {dor every }} \mathrm{w}^{\prime}, \mathrm{S}, \mathrm{w}^{\prime}, \mathrm{f} \vDash \mathrm{F}$; it is thus unnecessary to spell them out.

To see how this semantics applies to taste predicates, take the sentence "This is delicious." Its default translation will be DeLICIOUS $\mathrm{x}_{1} \mathrm{x}_{\mathrm{T}}$. If it is used by Tarek in reference to the ice-cream to express his own taste, then, in evaluating his utterance for a truth value, one will typically choose an assignment of values that sends $\mathrm{x}_{1}$ to the ice-cream and $\mathrm{x}_{\mathrm{T}}$ to Tarek. If Inma uses the same sentence in reference to the waffle to express her own taste, we will want to assign the waffle to $x_{1}$ and Inma to $x_{\mathrm{T}}$. On the other hand, if the sentence is used to make a universal claim, in the sense of 'delicious tout court', then its translation is going to be $\forall \mathrm{x}_{\mathrm{T}}$ DELICIOUS $\mathrm{x}_{1} \mathrm{x}_{\mathrm{T}}$.

Let me emphasize that by handling the judge argument by means of a variable, CS is not committed to the idea that I could say 'This is delicious' in reference to any salient judge to express their taste. Just as there are restrictions on what, in any given context, can be referred to with 'this', there are restrictions on the range of individuals plausibly assignable to $\mathrm{x}_{\mathrm{T}}$. These restrictions may be merely a pragmatic matter, or lexicalized to a certain extent, but they are not built into the semantics. Here again, CS and RS are on a par, since, similarly, restrictions on the range of values at which an utterance of a sentence can be plausibly evaluated for truth are not built into the semantics either.

Let us now turn to the relativist sibling of contextualist semantics. The difference is, roughly, that what the contextualist translates by a 2-place predicate one of whose arguments is occupied by the variable $x_{T}$, the relativist translates by a 1-place predicate. But on the semantic side, the interpretation of this 1-place predicate is not just a mapping from possible worlds to sets of individuals, but rather, from pairs $\langle$ world, individual $\rangle$ to sets of individuals. The framework that follows is as in Lasersohn (2005), 
except for some minor differences. ${ }^{15}$

The formal language of $\mathrm{RS}, \mathrm{L}_{\mathrm{RS}}$, is the language of quantified modal logic, the only novelty now being that we have a new operator, $\square$. The syntax of $L_{R S}$ consists of the standard rules for well-formedness, plus: if $F$ is a formula, so is $\square$ F. On the semantic side, a structure is, again, a triple consisting of a universe, a set of possible worlds, and a valuation that now maps any n-place predicate to a function that maps pairs consisting of a possible world and of an individual to sets of n-tuples of individuals. Truth is recursively defined at models, which are now quadruples of the form $\langle S, w, u, f\rangle$, where $S$ is a structure, $w$ a world, $u$ an individual (who serves as the value for the judge parameter), and $f$ an assignment of values to free variables. The definition of truth is, again, entirely standard. The only new truth clause (standard, too, in its kind) is: $S, w, u, f \vDash \square F$ iff def $_{\text {for }}$ every $u^{\prime}, S, w, u^{\prime}, f \vDash F$. In other words, $\square$ is what we might call the universal judge operator, used in accounting for the universal reading of claims about taste. ${ }^{16}$

To show the equivalence between CS and RS, we need to define a suitable translation between the two languages. This is made easy by the fact that $L_{C S}$ has a distinguished variable $x_{T}$, and that the definition of $\mathbf{a}$ not mediated by any accessibility relation. ${ }^{17}$ Here is the proposed

15 One difference is that, unlike Lasersohn, I am introducing $\mathbf{a}$ aniversal operator on the judge parameter. Another difference is that Lasersohn has a class of predicate modifiers 'for c' (where $\mathrm{c}$ is a constant), meant to translate complex expressions such as 'tasty for Tarek'. On the semantic side, 'for Tarek' works as a rigidifier: it makes the semantic value of 'tasty for Tarek' a constant function in the judge parameter, whose value, for any individual, is the same as the value that 'tasty' alone takes at Tarek. The way in which contextualist semantics would handle the adjunct 'for Tarek' is simply by making explicit the second argument of 'tasty', which, when implicit, is occupied by the variable $\mathrm{x}_{\mathrm{T}}$. Finally, Lasersohn's framework is cast within a Kaplanian framework, hence, besides the possible world parameter, it also uses a time parameter and a context parameter, both of which I am ignoring here.

16 Note that is unclear whether Lasersohn would acknowledge universal or even generic readings. If he were to do so, my hunch is that, rather than having an operator like he would use the construction 'for $\mathrm{x}^{\text {' }}$ and bind the variable $\mathrm{x}$ with a regular quantifier.

17 Even if we used an accessibility relation among judges, that would only entail a minor complication. In what follows, I rely on some known results from modal logic; see e.g. 
translation $T$ that takes $\mathrm{L}_{\mathrm{RS}}$-formulas to $\mathrm{L}_{\mathrm{CS}}$-formulas:

$$
\begin{array}{ll}
T\left(\mathrm{Pt}_{1}, \ldots, \mathrm{t}_{\mathrm{n}}\right)=\mathrm{P}^{T} \mathrm{t}_{1}, \ldots, \mathrm{t}_{\mathrm{n}}, \mathrm{x}_{\mathrm{T}} & \text { where } \mathrm{t}^{\prime} \text { s are either variables or constants } \\
T(\mathrm{~F} \wedge \mathrm{G})=T(\mathrm{~F}) \wedge T(\mathrm{G}) & \text { idem for other connectives } \\
T\left(\forall \mathrm{x}_{\mathrm{i}} \mathrm{Fx}_{\mathrm{i}}\right)=\forall \mathrm{x}_{\mathrm{i}} T\left(\mathrm{Fx}_{\mathrm{i}}\right) & \\
T(\mathbb{} \mathrm{F})=\forall \mathrm{x}_{\mathrm{T}} T(\mathrm{~F}) . &
\end{array}
$$

Remember that $\mathrm{L}_{\mathrm{RS}}$ handles the judge-dependence of taste predicates by means of an additional parameter in the definition of truth. $\mathrm{L}_{\mathrm{CS}}$, on the other hand, deploys no such parameter, but it has an additional argument place in every taste predicate. That is what translation $T$ reflects. In fact, $T$ "opens" a new argument place in every predicate, whether or not it is a taste predicate. For the latter, though, this argument will be idle. ${ }^{18}$ What the first clause says is, roughly, that if $\mathrm{P}$ is an n-place predicate in the language $L_{R S}$, then take an $(n+1)$-place predicate $\mathrm{P}^{T}$ in the language $\mathrm{L}_{\mathrm{CS}}$, and use variable $\mathrm{x}_{\mathrm{T}}$ in its last argument place. We also need to ensure that the structures of interpretation $S$ of $R S$ and $S^{T}$ of CS provide the (relevantly) same valuations for the two predicates:

- if $\left(\mathrm{w}, \mathrm{u},\left(\mathrm{u}_{1}, \ldots, \mathrm{u}_{\mathrm{n}}\right)\right) \in \mathrm{V}^{\mathrm{S}}(\mathrm{P})$, then $\left(\mathrm{w},\left(\mathrm{u}_{1}, \ldots, \mathrm{u}_{\mathrm{n}}, \mathrm{u}\right)\right) \in \mathrm{V}^{\mathrm{S} T}\left(\mathrm{P}^{T}\right)$.

What translation $T$ does, too, is translate the universal operator $\square$ by a universal quantifier that binds the judge variable $\mathrm{x}_{\mathrm{T}}$.

van Benthem (1983: 40).

18 In this respect, there will be a difference between the "direct" translation of a tasteinsensitive predicate from natural language into $L_{\mathrm{CS}}$, which is represented by a oneplace predicate letter $\mathrm{P}$, and the translation that we would get if we first translated it into $L_{R S}$ and then into $L_{C S}$ using the translation procedure $T$, since, then, it will be represented by a two-place predicate letter $\mathrm{P}^{T}$. On the semantic side, this difference is hardly noticeable - for, if $\mathrm{V}(\mathrm{P})$ is a function constant in the parameter $\mathrm{u}$, then $\mathrm{V}\left(\mathrm{P}^{T}\right)$ will be similarly "constant" in its last argument: if there is $a \in U$ such that $\left(a_{1}, \ldots, a_{n}, a\right) \in V\left(P^{T}\right)$, then any $b \in U$ must be such that $\left(a_{1}, \ldots, a_{n}, b\right) \in V\left(P^{T}\right)$. 
In the other direction, translation $T$ maps sentences of $\mathrm{L}_{\mathrm{CS}}$ to sentences of $\mathrm{L}_{\mathrm{RS}}$ as follows:

$$
\begin{array}{ll}
T\left(\mathrm{Pt}_{1}, \ldots, \mathrm{t}_{\mathrm{n}}, \mathrm{x}_{\mathrm{T}}\right)=\mathrm{P}^{\mathrm{T}} \mathrm{t}_{1}, \ldots, \mathrm{t}_{\mathrm{n}} & \\
T\left(\mathrm{Pt}_{1}, \ldots, \mathrm{t}_{\mathrm{n}}\right)=\mathrm{Pt}_{1}, \ldots, \mathrm{t}_{\mathrm{n}} & \\
T(\mathrm{~F} \wedge \mathrm{G})=T(\mathrm{~F}) \wedge T(\mathrm{G}) & \text { idem for other connectives } \\
T\left(\forall \mathrm{x}_{\mathrm{i}} \mathrm{Fx}_{\mathrm{i}}\right)=\forall \mathrm{x}_{\mathrm{i}} T\left(\mathrm{Fx}_{\mathrm{i}}\right) & \text { for any } \mathrm{x}_{\mathrm{i}} \neq \mathrm{x}_{\mathrm{T}} \\
T\left(\forall \mathrm{x}_{\mathrm{T}} \mathrm{Fx}_{\mathrm{T}}\right)=\mathbf{\square}\left(\mathrm{Fx}_{\mathrm{T}}\right) . &
\end{array}
$$

Again, we must ensure that the structures of interpretation $S$ of CS and $\mathrm{S}^{T}$ of RS will interpret the atomic predicates alike:

- if $\mathrm{P}$ is a taste predicate, then:

$$
\text { if }\left(w,\left(a_{1}, \ldots, a_{n}, a\right)\right) \in V^{S}(P) \text {, then }\left(w, a,\left(a_{1}, \ldots, a_{n}\right)\right) \in V^{S T}\left(P^{T}\right) \text {; }
$$

- otherwise:

$$
\text { if }\left(w,\left(a_{1}, \ldots, a_{n}\right)\right) \in V^{S}(P) \text {, then for all } b \in U,\left(w, b,\left(a_{1}, \ldots, a_{n}\right)\right) \in V^{s T}(P) .{ }^{19}
$$

The following equivalence results follow directly from the definitions of $T$, and may be verified by induction on the complexity of $F$.

$$
\begin{aligned}
& \text { claim 1: } \quad \mathrm{S}, \mathrm{w}, \mathrm{u}, \mathrm{f} \models_{\mathrm{RS}} \mathrm{F} \text { iff } \quad \mathrm{S}^{T}, \mathrm{w}, \mathrm{f}^{T} \models_{\mathrm{CS}} T(\mathrm{~F}) \text {, } \\
& \text { where } f^{T}\left(x_{T}\right)=u \text { and } f^{T} \text { is otherwise like } f \text {. }
\end{aligned}
$$

$$
\text { claim 2: } \quad \mathrm{S}, \mathrm{w}, \mathrm{f} \vDash_{\mathrm{CS}} \mathrm{F} \quad \text { iff } \quad \mathrm{S}^{T}, \mathrm{w}, \mathrm{f}\left(\mathrm{x}_{\mathrm{T}}\right), \mathrm{f} \vDash_{\mathrm{RS}} T(\mathrm{~F}) .
$$

19 Recall that in the language of CS, the judge argument is only associated with taste predicates. That is why we need the second clause in the translation procedure, as well as this constraint on interpretation structures: its task is to prevent the possibility of a judge-insensitive predicate from $\mathrm{L}_{\mathrm{cs}}$ being interpreted, in RS, by a function that varies in the judge parameter. 
The equivalence between CS and RS suggests that there is never going to be any properly semantic evidence to cut in favor of the one account over the other. In other words, no occurrence of a sentence containing a taste predicate will come out true in the one account and false in the other (provided, of course, that the individual assigned to the implicit argument in CS is the same as the individual taken as the value for the judge parameter in RS). In turn, this suggests that the contextualism/relativism debate becomes meaningful only when thought of as bearing on issues that go beyond semantics proper..$^{20}$ The debate might concern the syntax/ semantics interface, pragmatics, computational linguistics, or other areas. What is more, there might be reasons to use both an implicit argument and an additional parameter in the circumstances of evaluation. This has been done in the recent proposal by Stephenson (2007), for whom a predicate like 'tasty' is a two-place predicate that comes either with a silent nominal item $\mathrm{PRO}_{\mathrm{J}}$ that refers to the judge, or with a null referential argument, and who, at the same time, follows Lasersohn (2005) in taking the content of a sentence to be a function from (inter alia) judges into truth values. In this sense, her account brings contextualist and relativist semantics together. ${ }^{21}$

\section{Section 5. The Argument From What Is Said}

Let me end the paper by raising and discussing some considerations

20 Note that the contextualism/relativism debate is, in this respect, quite different from e.g. the contextualism/invariantism debate. The latter may be thought of as a semantic debate, given that contextualism and invariantism do not yield the same predictions of truth value.

21 Most of the present paper was written before I became familiar with Stephenson's proposal, which is partly why I have not paid more attention to it here. One point worth emphasizing, though, is that her motivations for having a judge parameter in the circumstance of evaluation do not rest on the idea of faultless disagreement. She writes: "[w]hen I say that disagreement is possible in a certain dialogue, I mean very narrowly that expressions like no (it isn't) and nuh-uh are allowed. I don't mean that we have an intuition that the speakers disagree about something, which may be a broader phenomenon. I also don't mean that the disagreement is necessarily a rational or sensible one to engage in." (2007: 493). 
related to the notion of what is said that, at a first glance, seem to tell against contextualist semantics of taste predicates. Consider:

11. This is delicious. (uttered by Tarek in reference to the chocolate cake)

12. This is delicious. (uttered by Inma in reference to the same chocolate cake)

13. This is delicious. (uttered by Tarek in reference to the soybean ice-cream)

Let us suppose that in the three cases, it is clear that the speakers are expressing their own taste. Now arguably, there is a strong intuition that Tarek in (11) and Inma in (12) have said the same thing, namely, that the cake is delicious, and arguably, there is an equally strong intuition that what Tarek said in (11) is different from that which he said in (13). Let us, for the sake of the argument, take those intuitions for granted. Then they may seem to pose a problem for the contextualist, for the following reason. The semantic representation of Tarek's utterance of (11) is not any more similar to the representation of Inma's utterance than it is to the representation of his utterance of (13). Indeed, (11) and (12) will only differ on the value assigned to the variable $\mathrm{x}_{\mathrm{T}}$, while (11) and (13) similarly differ only on the value assigned to the variable $x_{1}$ (taking DeLicious $x_{1} x_{T}$ as a translation for "This is delicious"). By contrast, a relativist might claim that this is not at all a problem for his or her account, because what is said, on the relativist account, is a content whose truth value varies with the judge, hence a content of which the value for the judge parameter is not constitutive, while the values assigned to the variables are. Such contents are the same for (11) and (12), namely DeLICIOUS $\mathrm{x}_{1}\left[\mathrm{f}\left(\mathrm{x}_{1}\right)=\right.$ chocolate cake], while those of (11) and (13) are different, since different values get assigned to $x_{1}$.

We should not dismiss easily the question of how well a given semantic account, that is, an account of meaning and truth, extends into an account of what is said. Nevertheless, it is not clear that these considerations cut sharply in favor of the relativist account, or undermine the contextualist account. It is beyond the scope of this paper to give a detailed argument, so let me simply outline a solution to the problem of what is said. 
The intuition that Tarek says different things in (11) and (13) comes from the fact that he is talking about different things, namely, the cake and the ice-cream, hence saying about different things that they are delicious. ${ }^{22}$ But in the contextualist view, Tarek in (11) and Inma in (12) are also, in a sense, talking about different things, since each is talking about his or her own taste. ${ }^{23}$ What the contextualist needs to explain, then, is why we do not have the intuition that they are saying different things; instead, we naturally report them as having said the same thing, namely, that the cake is delicious.

The explanation that I propose relies on the idea that talking about one's own taste is a way of talking about oneself, and on the fact that, in general, two persons who says the same thing about themselves are easily reported as having said the same thing. Consider:

14. I hate soybean ice-cream. (uttered by Inma)

15. Mary said that, too. (Tarek's reply to Inma)

As it stands, Tarek's report of what Mary said is ambiguous between what we may call a strict reading, on which Mary said that Inma hates soybean ice-cream, and a sloppy reading, on which she said that she herself hates it. There is thus an asymmetry between the ways in which 'this' and ' $\mathrm{I}$ ' pattern in reports of what is said. When 'this' is used in reference to different things, it is incorrect to report the two speakers as having said the same thing, unless the reporter makes it explicit that they said it about different things. For instance, "Inma said that the cake was delicious, and Tarek said the same thing about the ice-cream" becomes a fine report for (12)-(13). On the other hand, when ' $\mathrm{I}$ ' is used by different speakers, one

22 The idea that we don't just say things, but that we say them about things, may be seen e.g. in Donnellan (1966). I develop it in my (2007).

23 Cf. MacFarlane: "The contextualist takes the subjectivity of a discourse to consist in the fact that it is covertly about the speaker (or perhaps a larger group picked out by the speaker's context and intentions). Thus, in saying that apples are "delicious", the speaker says, in effect, that apples taste good to her (or to those in her group)" (2006: 18). 
may report them as having said the same thing without having to make it explicit that each was talking about himself or herself. ${ }^{24}$

The fact, then, that (11) and (12) may be so easily reported as saying the same thing, even though Tarek is expressing his own taste and Inma her own, may be seen as an instance of more general facts about reporting what is said when one is talking about oneself. ${ }^{25}$ To be sure, there will be differences between the sense in which when Inma says that she hates soybean ice-cream, she is talking about herself, and the sense in which when she says that the chocolate cake is delicious, she is talking about herself (in virtue of talking about her taste); in the one case, she is the grammatical subject, while in the other, the cake is the subject, not her taste. In the one case, reference to Inma is explicit (by means of ' $I$ '), in the other, reference to her taste is implicit; and so on. But the contextualist need not claim that the implicit judge argument works exactly like the first person pronoun - all that matters is that they pattern similarly in reports of what is said.

\section{Section 6. Conclusion}

One of the main goals of this paper has been to show that it makes little difference whether we go relativist or contextualist when deciding upon a semantic framework for taste predicates. Of course, it would be hasty to conclude that it makes no difference whatsoever. Considerations about syntax, pragmatics, or their interface with semantics, may well push us the one way or the other. The point, however, is that the semantic data alone are not sufficient to motivate the choice of relativist over

24 For a more detailed discussion of the asymmetries between the first person pronoun and the rest, see my (2006) and (2007: 107-115).

25 One might object that this cannot be the end of the story, because, when Inma utters (12), and someone replies to her "That's what Tarek said, too", the reply does not seem to be ambiguous: the reading on which Tarek said that the cake was delicious to Inma seems simply unavailable. I believe that the unavailability of this reading can be traced to the differences pointed out in what follows, in conjunction with more general pragmatic considerations. 
contextualist semantics (or the other way round). That is what the formal equivalence results from Section 4 seek to establish.

I did not try to argue that there is no possible motivation for relativism over contextualism. What I have argued, though, is that the two motivations most frequently appealed to by the relativists are not good enough. One has to do with explaining why speakers who express their own tastes are naturally reported as having said the same thing. In the last section, I explored the idea that talking about one's own taste is a way of talking about oneself, and I showed how it can account for the intuition that if both you and I say that a given thing is delicious, we have said the same thing. But the central part of the paper was devoted to the discussion of whether faultless disagreement motivates relativist semantics. I argued that it does not. In Section 2, I tried to show that there is no such thing as faultless disagreement, and that each prima facie instance of it dispells, upon analysis, either into a case of genuine disagreement, or into some form of misunderstanding. In Section 3, I argued that even if there were faultless disagreement, it could not be explained within a relativist framework (assuming that speakers are not "semantically blind"). So the take-home message, times and again, is that the choice between relativism and contextualism, at least when talking about taste, is pretty much a matter of taste.

\section{Cited Works}

van Benthem, J. (1983), Modal Logic and Classical Logic, Bibliopolis

Condoravdi, C. and J-M. Gawron, (1996), "The Context-Dependency of Implicit Arguments", in Kanazawa et al. (eds.), Quantifiers, Deduction and Context,

* This paper grew out of an email correspondence with Peter Lasersohn in the Fall of 2004 concerning his by now well-known paper. Earlier drafts of the present paper were presented at the workshop "Relativizing Utterance Truth" (Barcelona, September 2005) and at the IPrA panel on semantic relativism (Göteborg, July 2007). I am thankful to both audiences for discussion. I would also like to thank Julien Dutant, Pauline Jacobson, John MacFarlane, Stefano Predelli, Dan Zeman, and an anonymous referee for L\&P, for discussion and comments on earlier drafts. 
Talking about Taste: Disagreement, Implicit Arguments and Relative Truth / 24

CSLI Publications: 3-27

Donnellan, K. (1966), "Reference and Definite Descriptions", Philosophical Review 75: 281-303

Glanzberg, M. (2007), “Context, Content and Relativism”, Philosophical Studies 132: 1-16

Kaplan, D. (1989), Demonstratives, in Almog et al. (eds) Themes from Kaplan, Oxford University Press: 581-563

Kölbel, M. (2002), Truth Without Objectivity, Routledge

Lasersohn, P. (2005), "Context Dependence, Disagreement, and Predicates of

Personal Taste", Linguistics and Philosophy 28: 643-686

MacFarlane, J. (2007), “Relativism and Disagreement", Philosophical Studies 132: 17-32

Partee, B. (1989), “Binding Implicit Variables in Quantified Contexts”, Papers of Chicago Linguistic Society 25: 342-365

Predelli, S. (2005a), Contexts. Meaning, Truth, and the Use of Language. Oxford: Oxford University Press

Predelli, S. (2005b), "Painted Leaves, Context, and Semantic Analysis", Linguistics and Philosophy 28: 351-74

Stephenson, T. (2007), "Judge Dependence, Epistemic Modals, and Predicates of Personal Taste", Linguistics and Philosophy 30: 487-525

Stojanovic, I. (2006), “What Is Said, Linguistic Meaning, and Directly Referential Expressions", Philosophy Compass 1, http:// www.blackwellcompass.com/subject/philosophy/

Stojanovic, I. (2007), What Is Said. An Inquiry into Reference, Meaning, and Content, PhD Dissertation, Stanford University 